Peer review: This article has been subject to a double blind peer review process

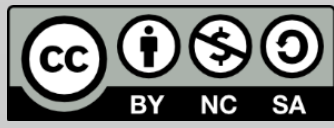

(C) Copyright: The Authors. This article is issued under the terms of the Creative Commons Attribution NonCommercial Share Alike License, which permits use and redistribution of the work provided that the original author and source are credited, the work is not used for commercial purposes and that any derivative works are made available under the same license terms.

\section{Enhancing the Employability of Chinese International Students: Identifying Achievements and Gaps in the Research Field}

\author{
Xuemeng Cao* \\ Centre for Education Studies, University of Warwick \\ *Correspondence: Xuemeng.Cao@warwick.ac.uk
}

\begin{abstract}
This article shows what achievements have been made by existing studies on graduate employability, and what gaps need to be filled in this field. It starts with a retrospective account of the changing concept of employability, followed by a presentation of the practices that have been used to support graduate employability enhancement in different countries. Moreover, this article gives a critical review of Chinese contexts of graduate labour market. Last but not least, limitations of existing studies are identified, which reflect an expectation for future research on graduate employability to meet the demand of an increasingly international dimension of higher education.
\end{abstract}

Keywords: graduate employability; Chinese international students

\section{Introduction}

There has been a dramatic increase in student international mobility in recent years. In 2015, an estimated five million students studied outside of their home countries (OECD, 2015). China is the world's largest source market of international students. There were 1,260,000 Chinese students who studied abroad in 2015, accounting for approximately $25 \%$ of all internationally mobile students in the world (Wang and Miao, 2016). Most Chinese students regard international experience as a significant stepping stone towards the success of future career (Sina Education, 2016; Mok, et al., 2017). However, as a rising number of international students come back to China to pursue their career, the competition in the Chinese labour market has become increasingly fierce. According to the Annual Report on the Development of Chinese Students Studying Abroad (2016) No.5 (Wang and Miao, 2016), although the returnees enjoyed an $85.9 \%$ employment rate within six months after graduation, 
only 3.5\% of them felt satisfied with their current jobs. Dissatisfaction expressed was attributed mainly to low salaries and the challenge of adapting to the Chinese working context. To be specific, nearly $80 \%$ of Chinese international students earn salaries lower than their expectations, with $49 \%$ of overseas graduates needing more than five years to recover the cost of learning abroad (CCG, 2016). Meanwhile, $53.8 \%$ of overseas graduates have difficulties in adjusting to Chinese working environments (CCG, 2016). The mismatches existing between their economic inputs (cost of overseas education) and outputs (starting salaries) make Chinese international students disoriented and frustrated once they return to China. Therefore, it is necessary to explore how international students can make full use of their overseas experiences to develop their employability so that they can succeed in the Chinese labour market.

The employability of university graduates has been a topic heatedly discussed in educational and economic domains over the past decades (e.g. McKnight, 1999; Knight, 2001; Andrews and Higson, 2008; Jackson, 2016). It is also attracting increasing interest among researchers who specialise in the education-to-work transition of new graduates. This paper starts with conceptualizing the term 'employability', followed by a brief presentation of the existing practices on graduate employability in different countries, and then gives a critical review of Chinese contexts of graduate labour market, hoping to identify achievements and gaps in this field.

\section{The concept of graduate employability}

Employability is a complex concept whose meaning has changed over time. The origin of the term 'employability' can be traced from the beginning of the 20th century on the basis of the dichotomy between 'employable' individuals who were willing and able to work versus 'unemployable' individuals who were incapable of work and needed support (McQuaid and Lindsay, 2005). Therefore, at the very initial stage, employability was a pure economic notion which stressed how the government could take measures to facilitate people, the most underprivileged people in particular, to realise full employment in the labour market. In the 1970s, the economic situation changed, and though the main purpose of promoting employability was still to stimulate employment, the emphasis on employability began to alter from employees' self-image and working attitude to their knowledge and abilities (Guilbert et al., 2016). 
Since the 1980s, the scope of employability has been expanded to involve the organisational level, focusing on developing employees' transferable skills and thus optimising on their flexibility within an organisation (Forrier and Sels, 2003). Until the 1990s, when the concept of employability was discussed, individual initiatives in gaining, maintaining and developing employability during a transition in the internal or external labour market were particularly focused. In addition, at that time, the attention shifted from those people deemed 'needy' to the entire population. All employees have been expected to take responsibility for their own career development (Fugate, 2006; Nauta et al., 2009). Nowadays, in the $21^{\text {st }}$ century, with the expansion of global higher education, graduate employability has become a popular topic (Rae, 2007; Smith et al., 2000; Moore and Morton, 2017), which is heatedly discussed by researchers, employers, university managers and policy makers.

In essence, the views on graduate employability can be divided into two main conceptual approaches. Some researchers and policy makers define employability in relation to an individual's human capital (Tomlinson, 2010), insisting that employability describes how individuals invest money, time and efforts in developing knowledge, skills, capabilities and other kinds of characteristics, so that they can better adapt to the demands of the labour market. However, others have critiqued this view, identifying a lack of concern with demand-side external factors and noting that employability is regarded as a relational, contextual and conflictual issue instead of an individual, consensual and empowering one (Tholen, 2015). Owing to the limitations of the labour market and the impacts of national differences in skill formation, graduate employability to a certain extent, cannot serve as an absolute notion only related to individual attributes. Employability may be considered as a relative term encompassing opportunities and inequalities in the contrast and comparison among peers (Brown et al., 2004). By taking both the supply-side and demand-side dimensions into consideration, McQuaid and Lindsay (2005) produced a model assessing graduate employability composed of three interactive attributors: individual factors (largely related to skills); personal circumstances (domestic responsibilities); and external factors (labour market conditions). This model not only disaggregates the different elements which exert impact on employability, but also emphasises their concrete inter-relatedness. Another framework which provides a good contribution to understanding graduate employability in relational as well as absolute terms was developed by Brown, Hesketh and Williams (2003). Graduate employability in this model is dichotomised into 'absolute' and 'relative' dimensions. Brown and his colleagues, on the one hand, acknowledge 
that employability is a set of individual attributes that should and can be improved through education and training. On the other hand, Brown realises one's employability is also influenced by external factors, for example, the material, social and cultural resources individuals can access and utilise (Tomlinson, 2008). By reviewing the existing research, Green et al. (2013) abstracted the important similarities of the main employability frameworks, adding support systems to them, and thus structured their newly revised employability framework with 'enabling support factors', 'individual factors', 'individual circumstances', 'employer/ organizational practices', 'local contextual factors' and 'macro level factors'. Based on this framework, Green and her colleagues also measured the relative significance of different elements on the employability of young people, older people and migrants.

\section{Different national practices in supporting graduate employability}

Graduate employability has become a prevalent topic fiercely discussed by academic researchers and policy makers worldwide as a response to the knowledge-driven economy and society. In Australia and New Zealand, various measurements, for example the National Qualifications Framework (NQF), have been taken to stimulate and assess the cultivation of graduate employability (Barrie, 2006; Kalfa and Taksa, 2015). In Canada and the USA, several universities evaluate students through work-based/work-related learning criteria (Cranmer, 2006). In Europe, nations such as the UK, Finland and Denmark have attempted to embed employability training into curriculum design. Moreover, the European Council (2012) set up a benchmark for graduate employability: by 2020, the share of graduates (in the age group of 20-34) being employed within 3 years after they have completed education or training should be at least $82 \%$. In South Africa, the NQF includes two sets of outcomes - 'critical and specific' - which contribute to graduates' personal development and the economic development of society (Harvey and Bowers-Brown, 2004).

In Asia, Japan's Ministry of Education, Culture, Sports, Science and Technology (2013) demands university graduates to possess 'Syugyoryoku' (based on the Seven Survival Skills proposed by Wagner in 2008) for the preparations of becoming socially and professionally independent (Ito, 2014). In Malaysia, the government and related departments have conducted several surveys on graduate employability and labour market conditions, showing that Malaysian graduates are 
unemployed not because they are unintelligent but rather because most of them lack 'soft skills' (Singh and Singh, 2008). In the Philippines, as one of the most important labour-exporting countries, the purpose of higher education is largely to provide student consumers with the best means to access lucrative opportunities in the job market. As such, colleges and universities are institutions that would not only enhance human capital for national development, but for exporting to other countries as well (Ortiga, 2015).

\section{Graduate employability in Chinese contexts}

In the early days of new China when its 'planned economy' was implemented, the difficulty posed by graduate employment did not exist because it was the responsibility of the government to allocate appropriate jobs to the whole labour force (Ren et al., 2011). Furthermore, at that time graduates were seen as a valuable human resource because higher education in China was not particularly welldeveloped. As such, once people had entered the university system, they were more or less guaranteed elite employments after graduation. In the 1980-1990s, the Chinese economy developed rapidly owing to the 'Reform and Opening' Policy of Deng Xiaoping in 1979, and the demand for graduates became strong. At the time, the rates of university student enrolment and graduation did not greatly increase, and as the government was still in charge of the job allocation of graduates, all graduates could succeed in entering the labour market (Yao, 2008). Since the late 1990s however, the authorities no longer allocated jobs to graduates, and the labour market decided on graduate employment. The dramatic development of a knowledge-driven economy provided a great number of opportunities of graduates to attain high achievements. From 1999 , in order to guarantee the talent supply for economic development, to increase consumption to stimulate domestic demand and to meet the national desire to access high education, China implemented a largescale expansion of university enrolment. Within only two years, the scale of university students in China became second only to the United States, accounting for $1 / 7$ of the world numbers (Yao, 2008). In 2002, the first generation of students who had benefited from the enrolment expansion were due to graduate. As the data shows, the total number of students who graduated from universities in 2002 was 1,450,000, increasing by $23.9 \%$ on the previous year's figures (Yao, 2008).

Indeed, it is widely believed the year 2002 was an important turning point for the Chinese graduate labour market. From this date the problem of graduate employment emerged and it has become increasingly serious each subsequent year. Driven by the problem of 
graduate employment due to a sharp increase in number of graduates, many Chinese researchers have devoted themselves to exploring the issues relating to graduate employability. Influenced by European researchers, the majority of studies conducted by Chinese researchers analyse graduate employability via two main dimensions: subjective graduate attributors (e.g. Ren, 2005) and objective labour market conditions (e.g. Wen, 2015; Dai, 2014).

From the perspective of subjective graduate attributors, Yan (2007) argued that employability is a set of comprehensive abilities related to occupations, including knowledge, skills, attitude, personality, mental endurance and social adaptability. Xie (2005) demonstrated that employability contains basic abilities (e.g. communication, motivation and adaptability), professional abilities (e.g. academic performance and professional skills) and otherness abilities (individuation, innovativeness and creativeness). He considered basic ability as a prerequisite, professional ability as key and otherness ability as a core of graduate employability. Ren (2005) proposed that graduate employability includes three levels. The first level is basic working abilities such as IT skills, foreign language, capacities of organising, communicating and teamwork as well as professional ethics. The second level is professional skills, for instance, problem analysing and solving, learning ability and innovation capability. The third level is job-hunting skills including the ability of collecting information, presentation skills and decision-making ability. Summarising the ideas of Chinese researchers who place emphasis on the absolute employability of graduates, there are three main respects contained in this term: individual factors, personal circumstances and individual strategies.

From the perspective of objective labour market conditions, similar to European studies, Chinese researchers also discuss factors that may influence the employment outcomes of graduates, for example, economic conditions (Sun, 2009; Wen, 2015; Zhao, 2015), government policies (Zhang and Jiang, 2009; Fan et al., 2011; Cui, 2015), gender (Wu, 2010; Li, 2012; Liu, 2011; Li, 2016) and background (Wang and Zhou, 2006; Dai, 2014; Zhang, 2014). Further a concept of strong Chinese characteristics - 'guanxi' (commonly conceptualised as interpersonal ties) - is discussed in particular.

\section{Gaps in the field}

Researchers and policy makers in many countries have made efforts to assist with graduate employability enhancement and evaluation.

However, almost all existing studies on graduate employability have a 
strong national focus, and few concentrate on the increasingly international dimensions of higher education and graduate employability. Chinese international students are the largest group of international students in six countries including the US, the UK, Germany, Australia, Canada and Japan (EOL, 2015). The majority of research on these students tends to focus primarily on their experiences of adaptation and integration in a new learning and living context in the receiving countries (Mathias et al., 2013; Zhou and Todman, 2008; Wang et al., 2011). The achievements of international students are evaluated in terms of language proficiency improvement, cognitive development, social integration, intercultural ability, and personal growth. Nevertheless, it is worth mentioning that all of these achievements also eventually benefit the transition of individuals to employment.

Some Chinese researchers mention the employability of Chinese overseas students as a part of their study, with a few advances being made in this area of scholarship. For example, Huang (2013) explored the importance of future career developments for Chinese students who study abroad. Li (2013) investigated to what extent the concepts of employability proposed by Brown and Hesketh applied to UK-educated Chinese students' engagements with global and local labour markets. Nonetheless, these is a great potential to deepen these explorations of how Chinese students understand the relationship between their overseas experiences and graduate employability, as well as how they manage their employability during their overseas learning and living. In addition, previous studies have another substantial limitation in that researchers have tended to regard Chinese students as a homogeneous group. It is not wise to overlook the diversity of students' experiences, even though they are of the same ethnic group and nationality. For instance, socioeconomic status, a variable commonly used in social science research, has rarely been used to categorise Chinese overseas students. It is possibly because most of Chinese students learning in foreign countries, especially Western countries, come from middle-class families (Mok et al., 2017). As Goodman (2008) suggested, it is unadvisable to describe Chinese students as being from similar 'middleclass' families, especially given that the term could be defined very differently in China. Therefore, it is important to consider students' individual particularities when discussing their understanding of and approaches to employability management. 


\section{Conclusion}

Graduate employability is a topic that is focused on by researchers, educators and policy makers in many countries, with many achievements having been made in relation to conceptual explorations and practices in assisting with graduate employability enhancement. However, given the globalisation of higher education, international concerns need to be included in studies of graduate employability. Chinese overseas students constitute the largest group in the international student market. An increasing number of mobile Chinese students choose to return to China to develop their career. The connections between international higher education and graduate employment in local labour markets are worthy of further exploration. Such connections not only confirm that international students' investment in their study is worthwhile, but also indicate broader benefits to global higher education. 


\section{References}

Andrews, J., and H. Higson (2008), 'Graduate employability, "soft skills" versus "hard" business knowledge: A European study', Higher Education in Europe, 33 (4), 411-22

Barrie, S. C. (2006), 'Understanding what we mean by the generic attributes of graduates', Higher Education, 51, 215-41

Brown, P., A. Hesketh and S. Williams (2003), 'Employability in a Knowledge-Driven Economy', Journal of Education and Work, 16 (2), 107-26

Brown, P., A. Hesketh and S. Williams (2004), The Mismanagement of Talent: Employability and Jobs in the Knowledge Economy, Oxford: Oxford University Press

Center for China and Globalization (CCG) (2016), Investigative report on Chinese Returnees Employment in 2016, http://www.ccg.org.cn/Research/View.aspx?ld=4592, accessed 2 May 2017

Cranmer, S. (2006), 'Enhancing graduate employability: best intentions and mixed outcomes', Studies in Higher Education, 31 (2), 169-84

Cui, X. (2015), 'Investigating the problems of graduate employment in Shandong from the perspective of governments', unpublished dissertation for Masters degree, Shandong University

Dai, X. (2014), 'Investigating the influence of sense of self-efficiency on enhancing the employability of graduates from poor families', Modern Enterprise Education, 16, 238-39

Education Online (EOL) (2015), The report of study abroad trends to 2014, http://www.eol.cn/html/lx/2014baogao/content.html, accessed 10 December 2015

European Council (2012), Council conclusions of 11 May 2012 on the employability of graduates from education and training: 2012/C 169/04, European Union, Luxembourg, June

Fan, C., X. Sun, L. Bai and R. Liu, (2011), 'Investigating the Chinese policies of graduate employment and enhancing graduate employability', Youth Literator, 21

Forrier, A. and L. Sels, (2003), 'The concept of employability: A complex mosaic', International journal of human resources development and management, 3 (2), 102-24 
Fugate, M. (2006), 'Employability in the new millennium', in Greenhaus, J. H., and Callanan, G. A. (eds.), Encyclopedia of career development, Sage, CA: Thousand Oaks, pp. 267-70

Goodman, D. (2008), The new rich in China: Future rulers, present lives. Oxford: Routledge

Green, A., M. de Hoyos, S-A. Barnes, D. Owen, B. Baldauf and H. Behle, (2013), 'Literature Review on Employability, Inclusion and ICT, Report 1: The Concept of Employability, with a Specific Focus on Young People, Older Workers and Migrants', JRC Technical Report (Report EUR 25794 EN), Editors: Institute for Prospective Technological Studies, Joint Research Centre, European Commission, Luxembourg: Publications Office of the European Union, JRC Technical Report

Guilbert, L., J L. Bernaud, and B. Gouvernet (2016), 'Employability: review and research prospects', International Journal for Educational and Vocational Guidance, 16 (1), 69-89

Harvey, L. and T. Bowers-Brown, (Winter 2004/5), 'Employability: crosscountry comparisons', Graduate Market Trends

Huang R. (2013), 'International experience and graduate employability: Perceptions of Chinese international students in the UK', Journal of Hospitality, Leisure, Sport \& Tourism Education, 13, 87-96

Ito, H. (2014), 'Challenges towards Employability: Higher Education's Engagement to Industrial Needs in Japan', Higher Education Studies, 4 (2), 1

Jackson D. (2016), 'Re-conceptualising graduate employability: the importance of pre-professional identity', Higher Education Research \& Development, 35 (5), 925-39

Kalfa, S., and L. Taksa, (2015), 'Cultural capital in business higher education: reconsidering the graduate attributes movement and the focus on employability', Studies in Higher Education, 40, 580-95

Knight, P. T. (2001), 'Employability and quality', Quality in Higher Education, 7 (2), 93-95

Li, C. (2012), 'Competency and Employability: the ways of cultivation of female graduate vocational abilities', Journal of Changsha University, 26 (3), 131-45

Li, H. (2016), 'The Research on How to Cultivate the Employability Skills of Female Students in Universities', Journal of Xichang College: Social Science Edition, 28 (2), 115-18 
$\mathrm{Li}, \mathrm{Z}$. (2013), 'A critical account of employability construction through the eyes of Chinese postgraduate students in the UK', Journal of Education and Work, 26 (5), 473-93

Liu, Q. (2011), 'The research on female graduate employability under the background of popularity of higher education', unpublished dissertation for Masters Degree, JiangXi University of Science and Technology

Mathias, J., M. Bruce, D. P. Newton, (2013), 'Challenging the Western stereotype: do Chinese international foundation students learn by rote?' Research in Post-Compulsory Education, 18 (3), 221-38

McKnight, A. (1999), Graduate employability and performance indicators: first destinations and beyond, CSU Limited

McQuaid, R. W. and C. Lindsay (2005), 'The Concept of Employability', Urban Studies, 42 (2), 197-19

Mok, H.K., X. Han, J. Jiang and X. Zhang (2017), 'International and transnational learning in higher education: a study of students' career development in China', Centre for Global Higher Education working paper series, Working paper 21

Moore, T., and J. Morton (2017), 'The myth of job readiness? Written communication, employability, and the "skills gap" in higher education', Studies in Higher Education, 42 (3), 591-09

Nauta, A., A. Vianen, B. Heijden, K. Dam and M. Willemsen (2009), 'Understanding the factors that promote employability orientation: the impact of employability culture, career satisfaction, and role breadth self-efficacy', Journal of Occupational and Organizational Psychology, 82 (2), 233-51

OECD (2015), 'Education at a Glance 2015', http://www.keepeek.com/DigitalAssetManagement/oecd/education/education-at-a-glance-2015 eag2015-en\#.WRh45rzytmA, accessed 2 May 2017

Ortiga, Y. Y. (2015), 'The flexible university: higher education and the global production of migrant labour', British Journal of Sociology of Education, 1-13

Rae, D. (2007), 'Connecting enterprise and graduate employability: challenges to the higher education culture and curriculum?' Education and Training, 49 (8/9), 605-19

Ren, J. (2005), 'Considerations of developing graduate employability', Education and Vocation, 6, 49-50 
Sina Education (2016), 'Big data of Chinese overseas students: How much do you know about study abroad?’, http://edu.sina.com.cn/a/2016-0218/doc-ifxprucu2962707.shtml, accessed 10 December 2015

Singh, G. K. G., and S. K. G. Singh, (2008), 'Malaysian graduates' employability skills', UNITAR e-Journal, 4 (1), 15-45

Smith, J., A. McKnight and R. Naylor, (2000), 'Graduate employability: policy and performance in higher education in the UK', The Economic Journal, 110 (464), 382-11

Sun, F. (2009), 'Investigating the cultivation of graduate employability under the background of financial crisis', Henan Social Sciences, 17 (5), 210-12

Tholen, G. (2015), 'What can research into graduate employability tell us about agency and structure?', British Journal of Sociology of Education, 36 (5), 766-84

Tomlinson, M. (2008) ' "The Degree is Not Enough": Students' Perceptions of the Role of Higher Education Credentials for Graduate Work and Employability', British Journal of Sociology of Education, 29 (1), 49-61

Tomlinson, M. (2010), 'Investing in the Self: Structure, Agency and Identity in graduates' Employability', Education, Knowledge and Economy, 4 (2), 73-88

Wagner, T. (2008), Global achievement gap: Why even our best schools don't teach the new survival skills our children need and what we can do about it, New York: Basic Books

Wang, H. and L. Miao (2016), Annual Report on the Development of Chinese Students Studying Abroad, No.5, http://www.ccg.org.cn/Research/View.aspx?ld=5418\# Toc462933274, accessed 2 May 2017

Wang, Q., R. Taplin, and A. M. Brown (2011), 'Chinese students' satisfaction of the study abroad experience,' International Journal of Educational Management, 25 (3), 265-77

Wang, Z. and X. Zou (2006), 'Study on the educational work on employability of graduates from poor families', Pioneering with Science \& Technology Monthly, 5, 120-21

Wen, Y. (2015), 'Study on Ways to Increase Ethnic University Students' Employment Ability under the Background of Economic New NormalAnalysis Based on Questionnaire', Journal of Research on Education for Ethnic Minorities, 5, 21-25 
Wu, J. (2010), 'Study on employability of female undergraduate based on the boundaryless career theory', unpublished dissertation for Masters degree, Donghua University

Xie, Z. (2005), 'Consideration of cultivating the employability of university students', Exploring Education Development, 1, 95-96

Yan, D. (2007) 'Study on the contracture and attributors of graduate employability', Qinghai Social Sciences, 6, 28-31

Yao, Y. (2008), 'Evolution and Trend of University Graduate Employment Problems in China', Population Journal, 167 (1), 10-14

Zhang, H. (2014), 'Research on Employment Competency of College Students from Poor Families', Journal of Northeastern University (Social Science), 16 (5), 486-91

Zhang, T. and Y. Jiang (2009), 'Study on policies of graduate employment based on the employability', Human Resource Development of China, 7

Zhao, P. (2015), 'Research on the difficulty of graduate employment in low-developed regions-take the Shangluo College as an example', unpublished dissertation for Masters degree, West North University

Zhou, Y. and J. Todman, (2008), 'Chinese Postgraduate Students in the UK:

A Two-Way Reciprocal Adaptation', Journal of International and Intercultural Communication, 1 (3), 221-43

\section{To cite this article:}

Cao, X. (2017). Enhancing the Employability of Chinese International Students: Identifying Achievements and Gaps in the Research Field. Exchanges: the Warwick Research Journal, 5(1), 77-89. Retrieved from: http://exchanges.warwick.ac.uk/index.php/exchanges/article/view/208 